\title{
Expatriates with cancer diagnosis in the United Arab Emirates, hanging on the edge
}

\section{Opinion}

The United Arab Emirates (UAE) is a relatively young country established in December 1971 and located in the southeast of the Arabian Peninsula. The population of the UAE has almost tripled between the 1990 and 2005 due to large inward migration with estimated population of 9.2 millions in $2013^{1}$ (population estimates: 287,000 in $1971,4.1$ million in $2005,8.3$ million in 2010). ${ }^{2}$ The majority of the population in 2013 (7.8 million) are expatriates from over 200 nationalities specially Asia, only 1.4 million (15.2\%) are Emirati (UAE) citizens. making UAE home to one of the world's highest percentage of immigrants. This multinational population with varying degree of education, religious and cultural backgrounds may pose a challenge for public health strategies. ${ }^{3}$

Most expatriates are from working class and constitute the major work force in the UAE. As per the UAE regulations all expatriates and residents are mandated to obtain a basic health insurance valid all the time to obtain a valid visa to secure a legal status in the UAE. ${ }^{4}$ All expatriates on work visa have their health insurance coverage linked to their work contracts. Once the work contract expires or canceled, the health insurance is automatically canceled. In our experience in the United States, reaching insurance annual or lifetime cap was a common concern for many patients prior to the Affordable Care Act, yet it has been a unique and eye-opening experience for us to see patients' major concern once they are diagnosed with cancer is whether they will be able to continue working while they are receiving cancer treatment or not and the extent of treatment on their ability to function and look normal. Of interest reaching the insurance annual cap is still an issue for all patients in the UAE including expatriates. Almost all expatriates with cancer diagnosis fear they will lose their job and hence their health insurance once they are not able to meet their job requirements or miss working days. This complex issue has been illustrated by a expatriate from Jordan who lost her job after her breast cancer diagnosis. ${ }^{5}$ The patient lost her job after her diagnosis and had to seek charity support to finish her cancer treatment.

The UAE rules and regulations are very protective for employee, yet employers can dismiss employee for under performance rather than medical condition. This is in accordance with Article 120 (e) of the Federal Law No. 8 of 1980 regulating Labour Relations in the UAE (the "Employment Law"), which states: "An employer may dismiss a worker without notice if the worker does not perform his basic duties under the contract of employment and persists in violating them despite the fact that he has been the subject of a written investigation for this reason and that he has been warned that he will be dismissed if such behaviour continues." ${ }^{, 7,7}$ Current regulations does not exclude medical conditions as an acceptable reason or cause for under performance as an exceptions for these rules.

Almost all expatriate cancer patients request their chemotherapy sessions to be held after hours or during the weekends to avoid missing working days. From our experience this can create a significant pressure on the chemotherapy infusion unit after-hours and during
Volume 9 Issue 5 - 2018

\author{
Humaid O Al-Shamsi ${ }^{1,2}$ \\ 'Department of Medicine, University of Sharjah, United Arab \\ Emirates \\ 2Emirates Oncology Society, United Arab Emirates
}

Correspondence: Humaid O Al-Shamsi, MD, MRCP (UK), FRCP(C), FACP, University of Sharjah, Sharjah, United Arab Emirates, Tel +9715063I5388,

Email Humaid.Al-Shansi@medportal.ca

Received: October 20, 2018 | Published: October 30, 2018

weekends. Many expatriate are concerned if their cancer diagnosis is shared with their employers which they are assured of their right of privacy and confidentiality.

We have experienced a significant number of expatriate cancer patients who lost their jobs in the middle of their treatment and they are left without health insurance or valid legal status to stay in the UAE and they are forced to leave to their home countries to seek continuation of their cancer treatment which most likely causes gaps and delays in their treatment plan. Further research is needed to assess the impact of such treatment gaps in this patients' population oncological outcome.

In our view, expatriates with cancer diagnosis in the UAE should be treated with special protective rules and regulations giving the seriousness of such diagnosis and also the nature of cancer treatment which could last for years or the patient's entire life. The uncertainty of cancer itself in addition to the financial impact of job loss and health insurance loss can lead to serious consequences and likely poor oncological outcome if the patient is not able to continue their cancer treatment. ${ }^{8-10}$ Further research is needed to evaluate how to improve access and maintain cancer treatment for this vulnerable patients' population.

\section{Acknowledgements}

None.

\section{Conflict of interest}

The author declares there is no conflicto of interest.

\section{References}

1. Blair I, Sharif AA. Population structure and the burden of disease in the United Arab Emirates. J Epidemiol Glob Health. 2012;2(2):61-71.

2. United Arab Emirates National Bureau of Statistics 2013.

3. Chaudhry, Suchitra Bajpai. What makes UAE a role model of cohesion. Gulf News; 2018.

4. Health insurance - The official portal of the UAE Government. 2018. 
5. https://www.thenational.ae/uae/health/employers-should-not-be-able-tofire-a-cancer-patient-1.661828

6. Employment laws and regulations. 2018.

7. Ashish Mehta. Be careful, you can be fired for non-performance. 2018.

8. Kathleen M Fenn, Suzanne B Evans, Ruth McCorkle, et al. Impact of financial burden of cancer on survivors' quality of life. Journal of Oncology Practice. 2014;10:332-338.
9. Zajacova, Dowd, Schoeni, et al. Employment and income losses among cancer survivors: estimates from a National Longitudinal survey of American families. Cancer. 2015;121(24):4425-4432.

10. Stacie B Dusetzina, Ethan Basch, Nancy L Keating. For uninsured cancer patients, outpatient charges can be costly, putting treatments out of reach. Health Aff (Millwood). 2015;34(4):584-591. 